\title{
Aparato institucional para a gestão do turismo: o caso do estado de Sergipe*
}

\author{
Marcilio de Medeiros Brito** \\ Maria Arlete Duarte de Araújo***
}

S U MÁRIO: 1. Introdução; 2. A gestão do turismo no estado de Sergipe; 3. Uma breve discussão sobre estrutura organizacional; 4. Metodologia; 5 . Análise dos dados; 6. Conclusões.

S U M MAR Y : 1. Introduction; 2. Tourism management in the state of Sergipe; 3. A brief discussion about organizational structure; 4. Method; 5. Data analysis; 6. Conclusions.

P AL A VR A S - CH A VE: estruturas; organizações; turismo; gestão.

KEY WORDS: structures; organizations; tourism; management.

O turismo é um fenômeno cuja importância vem crescendo no mundo contemporâneo. Devido ao seu caráter transversal e complexo, são múltiplos os desafios para o gerenciamento de suas atividades setoriais. Partindo dessas premissas, este artigo analisa de que forma a estrutura organizacional do turismo, da maneira como está configurada, dificulta a sua gestão no caso do estado de Sergipe. Para tanto, utilizou-se pesquisa documental e entrevistas com técnicos e gerentes das três unidades administrativas que compõem o aparato institucional de gestão do turismo. Os resultados revelaram que a estrutura organizacional prejudica a gestão do turismo na medida em que há sobreposições de função tanto intra quanto interorganizacionais, baixa institucionalização dos processos de planejamento, desenvolvimento e marketing turísticos, pouca articulação entre os órgãos.

\footnotetext{
* Artigo recebido em fev. e aceito em set. 2005.

** Técnico em políticas públicas e gestão governamental (gestor governamental). Mestre em administração — PPGA/UFRN. Endereço: Av. Adélia Franco, 3.165 — Grageru — CEP 40027-010, Aracaju, SE, Brasil. E-mail: marciliomedeiros@ig.com.br.

*** Diretora do Centro de Ciências Sociais Aplicadas da UFRN. Doutora em organização, recursos humanos e planejamento - Eaesp/FGV-SP. Endereço: Rua Nossa Senhora de Lourdes, 236, ap. 300 Tirol — CEP 59015-260, Natal, RN, Brasil. E-mail: dfb@digi.com.br.
} 


\begin{abstract}
Institutional apparatus for tourism management
The importance of tourism increases more and more in today's world. Due to its transversal and complex features, management of tourism activities has many challenges. This article analyzes how the organizational structure of tourism, as it is, makes tourism management difficult in the state of Sergipe, Brazil. For this purpose, the authors researched documentation and interviewed managers and technical personnel in the three administrative units that integrate the institutional apparatus for tourism management. The results revealed that the organizational structure impairs tourism management because, among other problems, there is an intra- and interoganizational overlap of functions, low institutionalization of planning, development and marketing processes, and little articulation among agencies.
\end{abstract}

\title{
1. Introdução
}

À medida que o turismo cresce e ganha importância, multiplicam-se os desafios para o gerenciamento de suas atividades setoriais. De um lado, a grandeza estatística dos números reunidos dá relevo às suas possibilidades para o crescimento econômico das destinações turísticas; enquanto, de outro, os efeitos desfavoráveis, do ponto de vista ambiental, social e cultural, alertam para a necessidade de repensar as estratégias de desenvolvimento de modo que possam ser garantidas condições essenciais de sustentabilidade dos pólos receptivos.

As décadas de 1980-90 foram caracterizadas por uma forte inclinação neoliberal nos direcionamentos assumidos pelo turismo. A Organização Mundial do Turismo (OMT) preconizava uma participação crescente da iniciativa privada na condução e execução de funções ligadas à área, gerando um processo de auto-regulamentação das atividades turísticas, e o Banco Mundial (BID) e o Fundo Monetário Internacional (FMI) incentivaram e pressionaram os governos de países em desenvolvimento privatizar empresas e adotar economias voltadas ao mercado (Beni, 2001).

No entanto, ao avaliar, em 1995, o sistema de turismo de seus países-membros, a OMT percebeu que o setor privado preocupou-se em explorar as atividades mais lucrativas de curto prazo, negligenciando a preocupação com os impactos sociais negativos (Holanda, 2003). A parceria entre Estado e empresariado passou a ser estimulada e os governos ressurgiram como única força capaz de enfrentar e corrigir tais distorções, mitigando as externalidades negativas e potencializando os efeitos positivos, sob a égide do bem comum. Como administrador do sistema de turismo, os governos, por intermédio da máquina pública, estabelecem direção e coordenação às ações setoriais do turismo. A configuração das estruturas organizacionais do turismo condiciona, em larga medida, o resultado dessa função de liderança. 
Partindo dessa constatação e com base na percepção de que o aparato institucional de gestão do turismo em Sergipe se mostrava, à primeira vista, imbricado e passível de dificuldades operacionais por conta disso, considerou-se que a temática justificava a realização de uma pesquisa.

Este artigo analisa de que forma a estrutura organizacional dos órgãos de turismo, da maneira como está configurada, dificulta a sua gestão em Sergipe.

No estado de Sergipe, o aparato institucional para a gestão do turismo é composto pela Secretaria de Estado do Turismo (Setur), pela Empresa Sergipana de Turismo (Emsetur), entidade vinculada à Setur, e pela Unidade Executora Estadual do Prodetur em Sergipe (UEE/SE), subordinada à Secretaria de Estado do Planejamento e da Ciência e Tecnologia (Seplantec).

Inicialmente, é apresentada a estrutura organizacional existente no âmbito do estado de Sergipe para a gestão do turismo. Em segundo lugar, as estruturas organizacionais são discutidas. Em terceiro lugar, mostra-se a metodologia adotada neste estudo. Em seguida, examina-se a estrutura de gestão do turismo que emerge a partir da percepção dos atores envolvidos com a problemática do turismo no estado de Sergipe, procurando apreender e entender as estruturas formais/reais. Por fim, as dificuldades de gestão do turismo no estado de Sergipe, com o aparato institucional existente são expostas.

\section{A gestão do turismo no estado de Sergipe}

O turismo está no elenco de preocupações às quais se dedica o Estado, no sentido de alcançar seus objetivos, principalmente o bem-estar e o desenvolvimento da coletividade. Elliott (1997) argumenta que só os governos têm força suficiente para garantir a estabilidade política, a segurança e a estrutura legal e financeira que o turismo requer. São os governos que fornecem, também, serviços essenciais e infra-estrutura. Ignarra (2002:125) considera que "não é possível produzir turismo sem que haja direta e indiretamente uma participação do poder público", pois a ação governamental tem papel estratégico no seu desenvolvimento.

As atribuições que os governos tomam para si no turismo, no geral, abrangem:

t planejamento setorial — proposição, execução e avaliação de planos, programas e projetos;

t promoção turística - divulgação do destino turístico junto aos mercados emissores;

t infra-estrutura urbana e de acesso; 
t fomento - incentivos, subvenções e financiamentos;

t coleta e avaliação de informações turísticas;

t captação de recursos e investimentos privados;

t conscientização turística;

t acompanhamento e controle - regulamentação e fiscalização do mercado turístico, qualidade do produto turístico, capacitação de recursos humanos.

Para compreender melhor o turismo e o papel do setor público com relação a ele, uma abordagem que oferece uma perspectiva integradora baseia-se na teoria dos sistemas. No Brasil, Beni (2001) aplicou fundamentos dessa teoria no desenvolvimento do Sistema de Turismo (Sistur). Tal sistema é composto por três grandes conjuntos: o das relações ambientais, o da organização estrutural e o das ações operacionais, bem como seus elementos ou subsistemas (ecológico, econômico, social e cultural, da superestrutura, da infra-estrutura, do mercado, da oferta, da demanda, de produção, de distribuição e de consumo) e as relações de interação entre eles.

Ao subsistema da superestrutura é atribuída a função de administração do Sistur, aqui entendida como a criação e execução de planos que envolvem os objetivos gerais de desenvolvimento do turismo, as políticas e as estratégias, o ordenamento e a utilização dos recursos, além do controle do rendimento do sistema, cabendo a ele efetuar ajustes e procedimentos de correção, a fim de otimizar o funcionamento do sistema global. Para a administração do sistema, convergem as ações de planejamento, organização, gestão e operação do turismo. A estrutura ou aparato institucional oficial público é o instrumento material que põe em funcionamento a operação do sistema de turismo. A ação estatal realiza-se pelos poderes públicos, que "são convertidos em agentes turísticos por meio dos órgãos da administração pública” (Montejano, 2001:13).

No Brasil, quase todos os estados federados possuem, igualmente, seus organismos oficiais de turismo. Ora são exclusivamente centralizados, ora uma combinação de um órgão centralizado, normalmente uma secretaria, e uma entidade descentralizada, na forma de autarquia, empresa pública ou sociedade de economia mista.

A atividade setorial do turismo é realizada, no estado de Sergipe, por três unidades: a Secretaria de Estado do Turismo (Setur), a Empresa Sergipana de Turismo S.A. (Emsetur) e a Unidade Executora Estadual do Prodetur em Sergipe (UEE/SE) ou simplesmente UEE.

A Emsetur é uma sociedade de economia mista, criada em 12 de maio de 1972. A Lei $\mathrm{n}^{\mathrm{0}}$ 4.749, de 17 de janeiro de 2003, altera a estrutura organizacional da 
administração pública estadual, cria a Secretaria de Estado do Turismo, vincula a ela a Emsetur e cria na estrutura da empresa a Diretoria de Eventos.

A Lei $n^{-}$4.826, de 16 de maio de 2003, dispõe sobre a organização básica da Setur e suas competências. O Decreto nํㅡ 22.006, de 14 de julho de 2003, institui o Fórum Estadual de Turismo (Fortur/SE) e trata da política estadual de turismo.

O Decreto $n^{\mathrm{o}}$ 15.193, de 19 de janeiro de 1995, institui a Unidade TécnicoAdministrativa dos Pólos Turísticos de Sergipe (Unitur), vinculada à Seplantec, para ser a unidade de coordenação, supervisão e administração das ações do Prodetur/NE. O Decreto no 21.814, de 24 de abril de 2003, institui a Unidade Executora Estadual do Prodetur em Sergipe (UEE/SE), no âmbito da Seplantec, sucedendo a Unitur.

De acordo com a legislação pertinente, a Setur possui, oficialmente, as seguintes competências básicas: programação, organização, execução e acompanhamento da política estadual de turismo; participação e acompanhamento de políticas públicas de turismo; desenvolvimento turístico; fomento e incentivo à atividade turística; ampliação e melhoria de espaços turísticos; realização de eventos para divulgação do estado; capacitação de mão-de-obra para o turismo; articulação de órgãos e entidades públicos e privados envolvidos ou interessados no desenvolvimento da atividade turística; planejamento, coordenação, fomento, estímulo e promoção turísticas.

À Emsetur compete, como estabelece o seu regimento interno: executar a política estadual de turismo; fomentar as iniciativas e os planos, programas e projetos que visem ao desenvolvimento do turismo; desenvolver, continuada e sistematicamente, estudos de natureza técnica para subsidiar o aproveitamento das potencialidades turísticas do estado; fazer o registro e classificar empresas turísticas; promover e incentivar a criação e o desenvolvimento do ensino profissional voltado ao turismo; estimular, promover e administrar bens e estabelecimentos públicos de interesse turístico; estimular, promover, organizar e coordenar a realização de eventos diversos; e participar financeiramente, de forma temporária, de empreendimentos turísticos.

A UEE/SE tem por finalidade a implantação e a articulação de todas as ações realizadas no âmbito do Prodetur, que incluem: no Prodetur I — projetos de ampliação, construção e modernização de aeroportos; obras múltiplas em transportes; saneamento básico; preservação e proteção ambiental; recuperação do patrimônio histórico; e desenvolvimento institucional de órgãos públicos responsáveis pelo planejamento e gestão da atividade turística (BNB, s.d.); e no Prodetur II — fortalecimento da gestão administrativa e fiscal dos municípios e da gestão municipal do turismo; gestão de resíduos sólidos; proteção e conservação de recursos naturais; proteção e conservação do patrimônio cultural; urbanização de áreas turísticas; planejamento estratégico e preparação de projetos; desenvolvimento institucional de secretarias de turismo e planejamento; campanhas de conscientização; treinamento e capacitação profissional; água e saneamento; obras de infra-estrutura; seminários, 
cursos e serviços de consultoria para promoção de investimentos do setor privado (BNB, 2004). Em Sergipe, o Prodetur II ainda não foi iniciado, uma vez que o contrato de subempréstimo entre o BNB e o estado não foi firmado.

A subordinação hierárquica da unidade executora do Prodetur à Secretaria de Planejamento, uma secretaria de natureza instrumental (Lei no 4.749 ), difere do padrão dominante da maioria dos estados do Nordeste. Conforme levantamento realizado, em 66,67\% dos casos, a UEE é ligada organicamente às secretarias competentes pelas atividades setoriais de turismo.

Essa diversidade na configuração estrutural do setor exige um melhor entendimento de pontos fundamentais referentes a estruturas organizacionais, seu desenho, principais aspectos, componentes básicos e relações estabelecidas a partir da disposição desses elementos, o que será feito a seguir.

A preocupação com o aparato institucional público justifica-se pelo fato de a gestão do turismo estar condicionada, em larga medida, pela configuração das estruturas organizacionais existentes, uma vez que estas servem de guia das relações entre as várias partes da organização, influenciando os modos de funcionamento e resultados alcançados, que geram ou não valor para os públicos beneficiários.

\section{Uma breve discussão sobre estrutura organizacional}

Estudar estruturas organizacionais reveste-se de importância capital quando se pretende entender a gestão. Para o turismo, essa discussão possui relevo especial devido à complexidade e transversalidade da atividade turística e a necessidade de interlocução, sincronia e coordenação de um conjunto diversificado de agentes públicos, privados, do terceiro setor e das comunidades locais.

Faria (1979) considera que a organização do trabalho corresponde à estrutura operacional, formada pela hierarquia de autoridade e pelo estabelecimento de tarefas, atribuições, deveres e responsabilidades, e cabe à administração, por meio da programação, coordenação e controle dos fatores humanos e materiais, pôr em funcionamento esse mecanismo.

Schermerhorn Jr. (1999:152) define estrutura organizacional como "o sistema de redes de tarefas, relações de quem se reporta a quem e as comunicações que inter-relacionam o trabalho de indivíduos e grupos". A estrutura formal é a estrutura da organização em seu estado oficial. A linha de autoridade flui pelos níveis hierárquicos, envolvendo a cadeia de comando, a unidade ou duplicidade de comando e a amplitude de controle.

A estrutura é o conjunto de relações relativamente fixas, resultante de processo decisório anterior, e abrange a definição de todas as tarefas; a divisão desse total em tarefas sucessivamente menores, a departamentalização ou recombinação e rea- 
grupamento das tarefas individuais, a amplitude de controle e a delegação ou distribuição da autoridade (Gibson, Ivancevich e Donnelly, 1981).

Matas (1999) argumenta que se pode observar a estrutura em duas dimensões. A hierarquia ou altura corresponde à sua dimensão vertical e faz referência ao número de níveis de direção ou mando. A altura relaciona-se, ainda, com a comunicação entre as unidades e com a velocidade dos processos decisórios. A departamentalização ou amplitude corresponde à dimensão horizontal da estrutura. Permite, a partir da especialização do trabalho, agrupar pessoas e atividades em unidades.

Megginson, Mosley e Pietri Jr. (1986) defendem que a departamentalização determina como as atividades são agrupadas na organização. Os tipos de departamentalização podem ser funcional, por produto ou serviço, territorial (ou por área geográfica), por cliente, por processo ou equipamento, por projeto e por matriz.

Schermerhorn Jr. (1999) argumenta que a departamentalização pressupõe diferenciação. Para superar a fragmentação advinda desse processo e para que sejam garantidos os objetivos organizacionais unitários, é necessário que sejam desenvolvidos mecanismos de integração, o que ocorre mediante sistemas ou mecanismos de coordenação e controle (Lawrence e Lorsch, 1973; Matas, 1999).

Newman (1977:360) diz que coordenação é "a fase que se ocupa da sincronização e unificação das atividades de um grupo de pessoas". Os principais mecanismos de coordenação são a adaptação mútua, quando a coordenação é obtida por meio da comunicação informal; a supervisão direta, quando a coordenação é conseguida pela responsabilização de uma instância pelo trabalho das demais; normatização, quando a coordenação é baseada na estruturação rigorosa do programa de trabalho; e unidades de coordenação, quando são criadas unidades interdepartamentais que coordenam diferentes âmbitos de gestão (Matas, 1999).

Para Megginson, Mosley e Pietri Jr. (1986:401), o controle é o “processo de garantir que os objetivos organizacionais e gerenciais estejam sendo cumpridos (...) do modo planejado". Os tipos de controle de supervisão podem ser: o controle de resultados, baseado em registros escritos que medem as saídas e a produtividade dos funcionários; o controle de procedimentos, baseado na observação pessoal do comportamento do funcionário durante o processo de trabalho; o controle de entradas, que utiliza a seleção e o treinamento para uniformizar conhecimentos, habilidades, valores etc. (Daft, 1999).

Os meios utilizados para efetuar controles auxiliam igualmente nas tarefas de coordenação. Alguns autores, inclusive, preferem tratar essas duas questões juntas, uma vez que parecem inextricavelmente interligadas.

Para que a coordenação seja eficaz, a comunicação é um elemento de consideração essencial. Ela pode ser entendida como o "fluxo de informação dentro da organização, através dos diversos canais e redes” (Robbins e Coulter, 1998:464). O processamento da informação pode ser estabelecido por meio de ligações verticais e 
horizontais. Ligação é “a extensão das comunicações e da coordenação entre os elementos organizacionais” (Daft, 1999:135).

As ligações verticais de informações são utilizadas para coordenar atividades entre os níveis hierárquicos da organização, do topo à base. Estas ocorrem através da referência hierárquica (ou hierarquia, ou cadeia de comando), uma vez que as linhas do organograma funcionam como canais de comunicação; de normas e planos, na medida em que normas e procedimentos dão soluções padronizadas para problemas rotineiros, e planos (como o orçamento) fornecem informações permanentes; e os sistemas de informações verticais, na forma de relatórios periódicos, informações escritas etc.

As ligações horizontais de informações são utilizadas para superar as fronteiras entre os departamentos, coordenando esforços. Os mecanismos de ligação horizontal muitas vezes não são representados no organograma, embora façam parte da estrutura da organização (Daft, 1999). Nesse plano, o intercâmbio de informações pode acontecer pelos sistemas de informação computadorizados; pelo contato direto de gerentes com gerentes, de gerentes com empregados e de empregados com empregados; forças-tarefa, que são grupos temporários compostos de representantes dos vários departamentos afetados por um problema ou questão; ou, ainda, integradores de tempo integral, quando se criam cargos ou departamentos com propósitos específicos de coordenação, podendo ser gerentes de projeto, de programa ou de marca.

A formalização visa imprimir ordem à estrutura, repercutindo nas funções de coordenação e controle dos recursos e processos de trabalho. Organogramas e descrição de atribuições são os instrumentos mais utilizados para formalizar uma estrutura (Vasconcellos e Hemsley, 2003). O organograma é um diagrama que representa de modo sintético a estrutura formal, enquanto manuais da organização, manuais de procedimentos, normativos em geral, descrição de cargos e documentação afim expressam a estrutura de modo analítico. O grau de formalização é definido pelo volume de documentação escrita existente na organização, por exemplo, procedimentos, descrições de cargos, regulamentos e manuais (Daft, 1999).

O grau de centralização vai possibilitar perceber questões tais como o controle sobre as decisões, a autonomia e a participação dos empregados na gestão. Centralização e descentralização têm a ver, respectivamente, com a concentração e dispersão da tomada de decisão na cúpula ou nos níveis inferiores da organização. Segundo Megginson, Mosley e Pietri Jr. (1986:238), “nenhuma organização é completamente centralizada ou descentralizada; o grau encontra-se ao longo de uma escala que vai desde alta centralização até alta descentralização”.

Esses são os principais componentes das estruturas formais. Da combinação dos diversos fatores já referidos, as estruturas podem assumir configurações variadas. 
O desvelamento dessa engrenagem permite observar aspectos essenciais para o entendimento das dificuldades e/ou facilidades do aparato institucional.

\section{Metodologia}

O objetivo desta pesquisa é analisar em que medida a estrutura organizacional dos órgãos de turismo dificulta a gestão do turismo em Sergipe.

Este estudo é uma pesquisa descritivo-exploratória. O método adotado foi qualitativo. Analisaram-se as compreensões e percepções dos respondentes sobre os pontos levantados. A unidade de análise é a organizacional e a perspectiva do estudo é do tipo transversal.

O universo pesquisado foi constituído de todos os gerentes de linha e staff, até o nível de departamento ou equivalente, e profissionais de nível superior envolvidos com as atividades-fim, lotados nas três unidades administrativas às quais incumbe a gestão do turismo na esfera estadual. O número total de informantes foi 26, sendo 14 informantes da Setur, sete da Emsetur e cinco da UEE/SE.

As variáveis foram definidas como a seguir.

Estrutura organizacional — operacionalizada neste estudo por meio da análise da estrutura formal das três unidades administrativas públicas responsáveis pela gestão do turismo no estado de Sergipe: Setur, Emsetur, e UEE/SE. A estrutura formal foi apreendida mediante a descrição e a análise dos seguintes indicadores:

t hierarquia — repartição e fluxo de autoridade;

t departamentalização — forma de distribuir e agrupar atribuições e pessoas;

t formalização - quantidade de documentação escrita que descreve aspectos da estrutura;

t coordenação - mecanismos de integração utilizados para gerar coesão entre as diversas unidades das organizações;

t controle - meios para garantir o cumprimento de tarefas e a condução de atividades conforme previsto;

t centralização/descentralização — concentração ou não da tomada de decisão nos níveis hierárquicos mais altos;

t comunicação - canais existentes para a realização da comunicação vertical, horizontal e diagonal. 
Gestão do turismo - entendida como a soma das competências administrativas de planejar, organizar, liderar e controlar as atividades setoriais do turismo. A gestão do turismo foi operacionalizada pelos indicadores a seguir:

t planejamento turístico - processo de definição de políticas, planos estaduais, programas e projetos turísticos;

t desenvolvimento turístico - compreendendo a atração de novos investimentos e empresas turísticas; instalação de infra-estrutura urbana, de acesso e de lazer; e capacitação profissional de recursos humanos para a atividade turística;

t marketing turístico - englobando a realização de estudos e pesquisa de mercado e a promoção turística voltados ao incremento da atividade turística, por meio da consolidação e ampliação da demanda, da taxa de permanência, do gasto médio diário etc.

Este artigo foi baseado em pesquisa bibliográfica, documental e de campo. A pesquisa de campo consistiu na realização de um survey, mediante entrevista estruturada, também chamada padronizada.

Com os dados obtidos, tanto documentais quanto empíricos, analisou-se a estrutura formal e o modo que ela estabelece como deveria ser a gestão do turismo por parte do estado, comparando como a gestão funciona na prática. A partir disso, verificou-se de que forma essa configuração formal e real dificulta a gestão do turismo.

\section{Análise dos dados}

Com referência aos componentes das estruturas formais, verifica-se que as três unidades estudadas possuem estruturas hierárquicas em que está preservado o princípio da cadeia de comando. Não há estruturas matriciais, o que faz com que a unidade de comando seja mantida.

A Setur e a Emsetur têm estruturas de linha e staff. No caso da Setur, são três os níveis hierárquicos, a amplitude da estrutura é pequena e a departamentalização é funcional. A UEE está inserida numa estrutura de linha e staff, a Seplantec. Tomada isoladamente, sua estrutura interna é do tipo linha e possui uma hierarquia de dois níveis. A departamentalização é por projeto, já que se trata de uma unidade executora de um programa de turismo. As unidades orgânicas que a compõem seguem uma departamentalização funcional, claramente separadas as atividades-meio, sob a responsabilidade da Coordenadoria Administrativo-Financeira, das atividades-fim, atribuídas à Coordenadoria Técnica. 
A estrutura da Emsetur contém quatro níveis de hierarquia e exibe um padrão misto de agrupamento de atividades. A departamentalização é, sobretudo, funcional. No caso da Gerência de Empreendimentos, que administra os equipamentos de lazer de propriedade da empresa, ela é geográfica (subdivide-se em unidades locais da capital e do interior).

A Emsetur, por ser uma sociedade de economia mista, segue alguns preceitos legais da administração pública direta, mas detém instrumentos próprios, como é o caso do estatuto social, do regimento interno e do manual de pessoal.

A Setur não possui manuais específicos. O que existe são instrumentos utilizados pela administração pública estadual como um todo.

A UEE também está sujeita às diretrizes e disciplinas da administração pública. Além disso, atende a exigências específicas consubstanciadas nos contratos e documentos do BID e do BNB. O principal deles é o Regulamento Operacional do Prodetur II. Quando cumprir as novas diretrizes do Prodetur/NE-II, estabelecidas pelo BID e pelo BNB, passará a ser uma estrutura muito formalizada. Por enquanto, é pouco formalizada.

As três unidades podem ser definidas, com base apenas na pesquisa documental, como burocracias mecanizadas ou detentoras de modelos clássico-burocráticos, que é, conforme apontado pela literatura, o modelo majoritário na administração pública. Com base nos meios de coordenação, controle e comunicação, e grau de centralização/descentralização, as estruturas podem ser consideradas hierárquicas tradicionais.

Tomando como referência a pesquisa de campo, essas considerações iniciais necessitam ser complementadas, principalmente quanto aos quatro elementos estruturais referidos por último - coordenação, controle, comunicação e centralização/ descentralização — que não se prestam a ser suficientemente compreendidos com base apenas nos organogramas e manuais.

Chegou-se à conclusão de que os principais mecanismos de coordenação adotados no três órgãos são o esforço espontâneo de coordenação exercido pelos próprios funcionários e a supervisão direta exercida pelo superior hierárquico. Não há grupos interdepartamentais, provisórios ou permanentes, nem um departamento formal ou unidade similar de coordenação, ferramentas úteis para integrar os subsistemas e grupos. Não há gerentes de projetos, que possibilitam aumentar a responsabilização e o controle dos resultados. Percebeu-se que os mecanismos são poucos e frágeis.

Os mecanismos de controle mais usados pelos três órgãos são a utilização de materiais e equipamentos, e controles financeiros, contábeis e orçamentários. Além disso, destacam-se, na UEE e na Setur, a supervisão direta da gerência e, na Emsetur, os relatórios escritos. Os normativos são quase inexistentes nos três, com ex- 
ceção da Emsetur. Os meios de controle voltados para resultados e desempenho são escassos.

Os canais de comunicação mais utilizados são a fala, o uso do telefone, circulares e quadro de avisos. As tecnologias da informação e reuniões de trabalho são pouco empregadas. Pelos resultados, a comunicação parece ocorrer de modo mais informal, pouco burocrático.

A participação no processo de tomada de decisão ocorre principalmente pela contribuição voluntária e informal e pela consulta formal aos técnicos e gerentes, o que revelou equilíbrio entre formas oficiais e espontâneas de participação e, conseqüentemente, certa equivalência entre centralização e descentralização das estruturas. A estrutura mais centralizada é a da UEE.

Pela análise documental, foi possível constatar que há diversas sobreposições de função, tanto intra quanto interorganizacionais. Os dados de campo ratificaram essa compreensão. Comparando a gestão do turismo formal e real é possível identificar as sobreposições existentes. Por se tratar de uma unidade, parte de uma organização maior — a Seplantec —, a UEE/SE é considerada, neste caso, como um todo. É possível observar, também, que não há zonas de neutralidade.

Com referência à gestão do turismo, o planejamento surge como uma função essencialmente técnica, feita por planejadores com participação do corpo gerencial e do trade turístico, em reuniões não-periódicas. Parece não ter dinâmica regular, atendendo a demandas pontuais.

As principais dificuldades são a desarticulação interinstitucional entre a Setur, Emsetur e UEE, a carência de recursos, a qualificação inadequada dos recursos humanos e a sobreposição de competências entre os três órgãos. As facilidades são poucas ou inexistentes e muitos entrevistados afirmam desconhecê-las. O planejamento é avaliado, pela maioria, negativamente ou como razoável.

O acompanhamento dos planos, programas e projetos setoriais é feito pela supervisão direta dos técnicos da área de planejamento. Este é praticamente o único mecanismo apontado, o que parece indicar que o acompanhamento é precário.

A tomada de decisão acerca da infra-estrutura é centralizada nas mãos dos dirigentes dos órgãos e do governador do estado, secundada pelos técnicos da área e pelo trade turístico.

A avaliação formal sobre esses investimentos em infra-estrutura parece frágil. Por sua vez, a avaliação da infra-estrutura instalada é, no geral, positiva. Há bastante desconhecimento sobre quem participa das decisões, como é feita a avaliação dos investimentos nessa área, e quais são as dificuldades e facilidades existentes.

Os dirigentes, principalmente o secretário de Turismo, são os agentes que têm maior poder de decisão sobre quais estratégias devem ser empregadas na atração de novos investimentos, o que caracteriza a centralização dessas atividades. O governador do estado participa, também, de modo ativo. Definidas de forma não-periódica, 
as estratégias mais empregadas são missões comerciais nacionais e internacionais, participação acionária em empreendimentos turísticos privados, parcerias com outras esferas de governo e instalação de infra-estrutura.

Há um enorme desconhecimento nessa área e acredita-se que ele se deva à centralização verificada. A maioria não sabe avaliar positiva ou negativamente as estratégias utilizadas, nem quais indicadores são definidos para medir os resultados da atração de investimentos, nem quais são as dificuldades e facilidades existentes nessa área.

O desconhecimento das ações de capacitação profissional é, igualmente, muito marcante. A maior parcela dos entrevistados não sabe quem são os agentes que participam das decisões, quais aspectos são considerados, e com que periodicidade, quais são os meios de verificação dos resultados das ações de capacitação e para que essas informações são usadas, quais as dificuldades e as facilidades existentes.

A função de estudos e pesquisas de mercado é cumprida principalmente pelos técnicos da área. O trabalho feito na área concentra-se em pesquisas, não aparecendo citação a estudos elaborados. As pesquisas realizadas recebem avaliação positiva. A finalidade principal das pesquisas é a verificação do produto turístico.

Entre as dificuldades enfrentadas, há destaque para a carência de recursos materiais, a falta de outras bases de dados socioeconômicos confiáveis no estado e escassez de recursos humanos.

As estratégias de promoção turística são diversificadas. São especialmente empregadas a divulgação na imprensa, famtour (familiarização turística) para jornalistas especializados, participação em eventos internacionais, material promocional, balcão de informações turísticas, campanhas publicitárias e criação de marca e slogan.

Participam, com igualdade de importância, técnicos da área e dirigentes dos órgãos na definição das estratégias utilizadas. As mídias aplicadas na promoção turística são jornal, revistas, folheteria, home page institucional, televisão, outdoor e rádio. As dificuldades enfrentadas na promoção turística são carência de recursos financeiros e materiais, e falta de qualificação dos recursos humanos.

Há desconhecimento acerca de diversas questões relacionadas à área. Muitos não sabem quais indicadores são utilizados para medir os resultados das ações de promoção, nem se as informações obtidas são aproveitadas em alguma coisa, nem se há facilidades para o desenvolvimento das atividades. Uma grande parte considera não ser utilizado nenhum indicador, nem haver emprego das informações coletadas.

É praticamente inexistente o processo de avaliação na UEE e na Emsetur. Na Setur, é realizada avaliação de desempenho institucional, embora sem periodicidade. Um grande contingente argumenta não ser realizado nenhum tipo de avaliação ou não saber que avaliações são levadas a cabo. 
A forma principal de articulação entre a Setur, a Emsetur e a UEE é informal, por meio de contatos pessoais. Os mecanismos formais funcionam de modo secundário, mediante reuniões de trabalho e documentos escritos.

Os principais empecilhos para o fortalecimento do relacionamento interinstitucional são a sobreposição de competências entre os órgãos, a existência de interesses pessoais que são colocados acima dos organizacionais, as estruturas organizacionais avaliadas como inadequadas e a falta de interesse dos dirigentes em melhorar esse relacionamento.

Para melhorar o relacionamento interinstitucional, as alternativas apontadas são a reestruturação do sistema Setur, Emsetur e UEE como um todo, a construção de uma visão de conjunto entre os funcionários dos três órgãos, a mudança de mentalidade dos gerentes e vontade política.

O ponto forte mais marcante dos três órgãos considerados em conjunto é a missão institucional claramente estabelecida. Além disso, a UEE possui estratégias adequadas e estrutura organizacional condizente.

O ponto fraco mais lembrado é a carência de recursos materiais, humanos e financeiros, constatação que já havia surgido ao longo da análise, aparecendo como um dos principais problemas do planejamento e das áreas de pesquisas de mercado e de promoção turística. Outros pontos fracos, citados pela maioria dos respondentes: a falta de coordenação efetiva das ações, disputas internas de poder entre pessoas e grupos, falta de planejamento, utilização de estratégias equivocadas e equipe desarticulada. Há predominância dos pontos fracos sobre os fortes.

\section{Conclusões}

É possível afirmar que a resposta ao problema de pesquisa foi se desvelando e construindo a partir da assunção dos dados coletados e de seu poder de expressão facilitado pela análise. Em síntese, a estrutura organizacional do turismo do governo de Sergipe dificulta a gestão do turismo no estado.

As sobreposições de competências começam nos instrumentos legais de criação dos órgãos, nos quais uma mesma função é atribuída a várias unidades de uma mesma organização e/ou a vários órgãos. A estrutura formal, que deveria ordenar e facilitar o funcionamento das organizações, cria, desde o início, confusão e conflito.

A gestão, pondo a estrutura em funcionamento (ou mesmo moldando-a e adaptando-a), deveria tentar corrigir ou aperfeiçoar as distorções. Não é isso que parece acontecer. A estrutura real cristaliza, se não as mesmas, outras sobreposições de função. Isto é particularmente preocupante em uma estrutura nova como a da Secretaria de Turismo.

O fracionamento da gestão do turismo em diversos órgãos, que pretendia dividir para realizar melhor, terminou por gerar compartimentalização e encastelamen- 
to das organizações. A existência de unidades ligadas a duas secretarias de estado torna mais complexa a gestão do turismo, tomado como algo único que é. As forças centrífugas impedem que os três órgãos funcionem como um sistema ou rede organizacional que trabalha o mesmo objeto, no caso o turismo.

Se a idéia fosse criar competências concorrentes ou reforçar a gestão com esforço conjunto de agentes, os mecanismos de coordenação, tanto intra quanto interorganizacional, deveriam ser objetivos, sistemáticos e formalmente definidos. Não é o que acontece, uma vez que os instrumentos usados são escassos e frágeis. Os mecanismos internos existentes são, acima de tudo, realizados pelos próprios funcionários ou pela supervisão do chefe, a quem é possível apenas em parte integrar o trabalho de indivíduos, grupos e de subsistemas entre si. Não é o que ocorre também com a comunicação e a articulação interinstitucional, ambas realizadas, sobretudo, de modo informal.

As estruturas assumem uma configuração tradicional, mecanicista, embora pouco formalizadas, quando, na realidade, processam atividades não-rotineiras e não-repetitivas. $\mathrm{O}$ trabalho realizado exige autonomia, criatividade e soluções inovadoras, cuja dinâmica esbarra na configuração estrutural. Um desenho mais orgânico deveria ser explorado para essas atividades.

O processo de tomada de decisão, considerado equilibrado entre centralização e descentralização, alivia a rigidez, propiciando a participação e, conseqüentemente, o comprometimento dos funcionários com a gestão. No entanto, em várias funções, tais como infra-estrutura e atração de investimentos, as decisões são bastante centralizadas, restritas a muito poucos.

A falta de periodicidade e método prejudica o andamento mais ou menos uniforme do processo de trabalho de diversas áreas, entravando o alcance de alguma previsibilidade e institucionalização de funções vitais, a exemplo do planejamento turístico, acompanhamento dos programas e projetos, e avaliação da gestão.

O desconhecimento, por parte de técnicos e gerentes, de questões essenciais do funcionamento dos órgãos e do dia-a-dia da atividade turística é um ponto merecedor de atenção especial.

A falta de utilização de indicadores da gestão, em diversas áreas, não permite quantificar ou qualificar o trabalho desenvolvido. Não possibilita também estabelecer padrões pretendidos, avaliá-los ou corrigir rumos com base nesses paradigmas predefinidos. Quando são utilizadas, as informações advindas dessas medidas de verificação são pouco ou nada aproveitadas.

Há acertos em alguns campos, tais como infra-estrutura, e estudos e pesquisas, mas estes se ressentem de uma extensa gama de empecilhos que os ofuscam.

Pelo exposto, fica reafirmada a conclusão que, de fato, o aparato institucional, da forma como está configurado, dificulta a gestão do turismo. A identificação e reflexão acerca de diversos problemas organizacionais, pelo corpo técnico e geren- 
cial, fornecem inúmeros indicativos de potencialidades inexploradas. É o que se espera seja uma das contribuições principais deste estudo.

Esta pesquisa não exaure o assunto, principalmente pela multiplicidade de ângulos com que as questões levantadas podem ser percebidas e investigadas. Convém ressaltar, ao final, que, apesar das limitações existentes, considera-se que esta pesquisa atingiu plenamente os objetivos propostos.

\section{Referências bibliográficas}

BENI, Mário Carlos. Análise estrutural do turismo. 6. ed. São Paulo: Senac, 2001.

BNB (BANCO DO NORDESTE). Prodetur/NE em ação: ações estruturantes do turismo no Nordeste do Brasil. Fortaleza: BNB, s.d.

. Regulamento operacional do Prodetur/NE II. Fortaleza: BNB, 2004.

DAFT, Richard L. Teoria e projeto das organizações. 6. ed. Rio de Janeiro: LTC, 1999.

ELLIOTT, James. Tourism: politics and public sector management. London: Routledge, 1997.

EMSETUR (EMPRESA SERGIPANA DE TURISMO). Estatuto. Aracaju: Emsetur, 1999. Regimento interno. Aracaju: Emsetur, 2003.

FARIA, Nivaldo Maranhão. Introdução à administração: perspectiva organizacional. Rio de Janeiro: LTC, 1979.

GIBSON, James L.; IVANCEVICH, John M.; DONNELLY, James H. Organizações: comportamento, estrutura, processos. São Paulo: Atlas, 1981.

HOLANDA, Luciana Araújo. Formação e institucionalização do campo organizacional do turismo no Recife - PE. 2003. 158 f. Dissertação (Mestrado em Administração) — Programa de PósGraduação em Administração, Universidade Federal de Pernambuco, Recife.

IGNARRA, Luiz Renato. Fundamentos do turismo. São Paulo: Pioneira Thomson Learning, 2002.

LAWRENCE, Paul R.; LORSCH, Jay W. As empresas e o ambiente: diferenciação e integração administrativas. Petrópolis: Vozes, 1973.

MATAS, Carlos Ramió. Teoria de la organización y administración pública. Madrid: Tecnos, 1999.

MEGGINSON, Leon C.; MOSLEY, Donald C.; PIETRI JR., Paul H. Administração: conceitos e aplicações. São Paulo: Harbra, 1986.

MONTEJANO, Jordi Montaner. Estrutura do mercado turístico. São Paulo: Roca, 2001. 
NEWMAN, William H. Ação administrativa: as técnicas de organização e gerência. 4. ed. São Paulo: Atlas, 1977.

ROBBINS, Stephen P.; COULTER, Mary. Administração. 5. ed. Rio de Janeiro: PHB, 1998.

SCHERMERHORN JR., John R. Administração. 5. ed. Rio de Janeiro: LTC, 1999.

SERGIPE. Lei no 1.721 , de 9 de dezembro de 1971. Autoriza o Poder Executivo a constituir a Empresa Sergipana de Turismo S.A. (Emsetur) e dá outras providências. Diário Oficial [do] Estado de Sergipe. Poder Executivo, Aracaju, 10 jan. 1971.

Lei n⿳0 2.148, de 21 de dezembro de 1977. Institui o regime jurídico dos funcionários civis do estado de Sergipe e dá providências correlatas. Diário Oficial [do] Estado de Sergipe. Poder Executivo, Aracaju, 22 dez. 1977.

. Lei n⿳⺈ 2.804, de 22 de junho de 1990. Dispõe sobre plano de cargos, funções e vencimentos ou salários, institui plano de carreira dos servidores públicos civis da administração direta, autarquias e fundações públicas do estado de Sergipe, e dá outras providências. Diário Oficial [do] Estado de Sergipe. Poder Executivo, Aracaju, 27 dez. 1990.

Decreto no 15.193 , de 19 de janeiro de 1995. Institui a Unidade Técnico-Administrativa dos Pólos Turísticos de Sergipe (Unitur), e dá outras providências. Diário Oficial [do] Estado de Sergipe. Poder Executivo, Aracaju, 20 jan. 1995.

. Lei Complementar no 33, de 26 de dezembro de 1996. Institui o Código de Organização e de Procedimento da Administração Pública do Estado de Sergipe. Diário Oficial [do] Estado de Sergipe. Poder Executivo, Aracaju, 28 dez. 1996.

Secretaria de Planejamento e da Ciência e Tecnologia. Perfil da administração pública do estado de Sergipe. Aracaju, 2002.

. Lei $\mathrm{n}^{\mathrm{0}}$ 4.749, de 17 de janeiro de 2003. Dispõe sobre a estrutura organizacional da administração pública estadual, e dá providências correlatas. Diário Oficial [do] Estado de Sergipe. Poder Executivo, Aracaju, 20 jan. 2003a.

. Decreto n- 21.814, de 24 de abril de 2003. Institui a Unidade Executora Estadual do Prodetur em Sergipe, no âmbito da Secretaria de Estado do Planejamento e da Ciência e Tecnologia (Seplantec), e dá providências correlatas. Diário Oficial [do] Estado de Sergipe. Poder Executivo, Aracaju, 25 abr. 2003b.

. Lei $n^{0}$ 4.826, de 16 de maio de 2003. Dispõe sobre a organização da Secretaria de Estado do Turismo (Setur), e dá providências correlatas. Diário Oficial [do] Estado de Sergipe. Poder Executivo, Aracaju, 22 maio 2003c.

Decreto nº 22.006, de 14 de julho de 2003. Dispõe sobre a Política Estadual de Turismo, institui o Fórum Estadual do Turismo e dá providências correlatas. Diário Oficial [do] Estado de Sergipe. Poder Executivo, Aracaju, 17 jul. 2003d. 
—. Lei no 4.912, de 22 de agosto de 2003. Dispõe sobre a Unidade Executora Estadual do Prodetur (UEE/SE-Prodetur), da Secretaria de Estado do Planejamento e da Ciência e Tecnologia (Seplantec). Diário Oficial [do] Estado de Sergipe. Poder Executivo, Aracaju, 25 ago. 2003e.

Secretaria de Planejamento e da Ciência e Tecnologia. Assessoria Técnica. Perfil da administração pública do estado de Sergipe. Aracaju, 2004. Disponível em: <www.seplantec. se.gov.br>. Acesso em: 21 abr. 2004.

VASCONCELLOS, Eduardo; HEMSLEY, James R. Estrutura das organizações. 4. ed. São Paulo: Pioneira Thomson Learning, 2003. 